\title{
РОЛЬ СИСТЕМЫ ТОРГОВОГО РАЙОНИРОВАНИЯ В ФОРМИРОВАНИИ ФИРМ С КРУПНЫМ КАПИТАЛОМ В GЕВЕРО-ВОСТОЧНОЙ СИБИРИ ВО ВТОРОЙ ПОЛОВИНЕ XIК - НАЧАЛЕ XК ВВ.
}

Аннотация. В статье проанализировано влияние системы торгового районирования на формирование фирм с крупным капиталом в Северо-Восточной Сибири во второй половине XIX - начале XX вв. В статье определено, что система торгового районирования влияла на формирование системы скупки пушнины у промыслового населения и торговую специализацию крупных фирм. В конце XIX в. темпы роста капитала были наиболее высокими в северных и северо-восточных промысловых районах, богатых ценными сортами пушнины. Система торгового районирования в пушной торговле сдерживала развитие свободной конкуренции между фирмами. Сделки с промысловым населением заключались в натуральной или натурально-денежной форме. Стоимость товаров потребления включала купеческую наценку. Анализ нескольких примеров заключения сделок с пушниной позволил сделать вывод о том, что промысловое население находилось в состоянии постоянного долга своему купцу, который постепенно приобрел статус кредитора. В рамках системы торгового районирования был создан торговый аппарат фирм, состоявший из агентов, доверенных лиц, приказчиков и клиентов. В статье отмечено, что система торгового районирования влияла на формирование рыночной стоимости пушнины. Чем более был удален промысловый район от Якутской ярмарки, тем выше была рыночная стоимость пушнины. Автор указал, что в начале XX в. в пушной торговле в Северо-Восточной Сибири 
под воздействием системы торгового районирования сформировалось несколько фирм с крупным капиталом, обладавших развитым торговым аппаратом и внутренней специализацией.

Ключевые слова. Крупный капитал, пушная торговля, Северо-Восточная Сибирь, купечество, фирма, прибыль.

\author{
M. D. Kushnareva \\ Irkutsk State University, \\ Irkutsk, Russian Federation
}

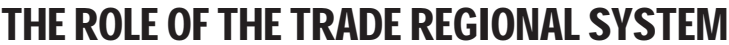

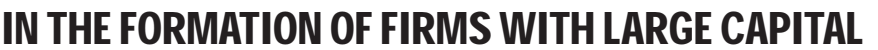 IN THE NORTH-EASTERN SIBERIA IN THE SECOND HALF

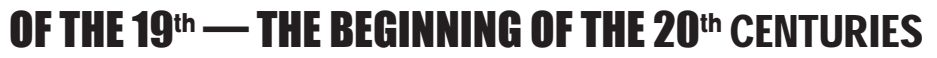

Abstract. The article analyzes the influence of the system of commercial zoning on the formation of firms with large capital in North-Eastern Siberia in the second half of the $19^{\text {th }}-$ early $20^{\text {th }}$ centuries. The article specifies that the system of commercial zoning influenced the formation of the system of fur buying from the commercial population and the trade specialization of large firms. At the end of $19^{\text {th }}$ century the growth rates of capital were the highest in the northern and north-eastern fishing areas abundant with valuable varieties of furs. The system of commercial zoning in fur trade inhibited the development of free competition between firms. Transactions with the fishing population were in natural or in kind monetary form. The cost of consumer goods included a merchant's margin. An analysis of several examples of transactions with furs has led to the conclusion that the commercial population was in a state of permanent debt to its merchant who gradually acquired the status of a creditor. Within the system of trading regionalization, a trading apparatus of firms was created, consisting of agents, proxies, clerks and customers. The article notes that the system of commercial zoning influenced the formation of the market value of furs. The more the fishing area was removed from the Yakut fair, the higher was the market value of furs. The author 
pointed out that at the beginning of the $20^{\text {th }}$ century in the fur trade in North-Eastern Siberia, under the influence of the system of commercial zoning, several large firms with a developed trading apparatus and internal specialization were formed.

Keywords. Large capital, fur trade, North-Eastern Siberia, merchants, firm, profit.

В современной российской историографии процесс формирования фирм с крупным капиталом в пушной торговли на северо-востоке Сибири остается еще не достаточно изученным. Между тем, главной особенностью процесса концентрации капитала в отрасли являлось наличие своеобразной системы торгового районирования, суть которой заключалась в том, что у каждого купца на стадии формирования крупного капитала была определенная территория производства торговых операций. Особенности размещения пушных ресурсов в районе скупки пушнины прямым образом определяли темпы роста капитала и торговую специализацию фирмы.

Следует отметить, что отдельные признаки наличия системы торгового районирования в пушной торговле в Северо-Восточной Сибири в период модернизации российской экономики выделял М. М. Константинов [2]. По мнению В. М. Зензинова система торгового районирования оказала непосредственное влияние на появление внутренней специализации крупных фирм [1, с. 14]. Отсутствие специальных работ по проблеме формирования фирм с крупным капиталом на территории Сибири отметил А. В. Старцев [4]. Таким образом, ученые определили, что система торгового районирования в пушной торговле играла определенную роль в формировании фирм с крупным капиталом и указали на необходимость дальнейшего изучения данной проблемы.

Основной целью публикации является выявление влияния системы торгового районирования в пушной 2018. T. 19, № 1. C. 79-90 
торговле на формирование фирм с крупным капиталом в Северо-Восточной Сибири.

Организация пушной торговли в период концентрации капитала строились на принципе разделения территорий и промыслового населения, что влекло отсутствие конкуренции между купцами. Как правило, район торговых операций определенного купца ограничивался естественными природными рубежами.

Северные промысловые районы, расположенные вдоль побережья Северного Ледовитого Океана, наиболее богатые ценными видами пушнины, были охвачены коммерческой деятельностью предприятий И. Г. Громова, А. М. Кушнарева, Я. Ф. Санникова. Так, в 1898 г. предприятием Громова в северных промысловых районах было скуплено 189 тыс. шкурок темной колымской белки, 10,5 тыс. шкурок белого песца, 260 шкурок лисицы сиводушки. В этом же году, в пользу купца А. М. Кушнарева в северных промысловых районах Якутской области было скуплено 17,5 тыс. шкурок темной белки, 1,1 тыс. шкурок красной лисицы, 7,5 тыс. шкурок песца. Санников Я. Ф. скупил 11 тыс. шкурок песца ${ }^{1}$. Общая стоимость скупленной пушнины в северных промысловых районах в 1898 г. предприятием Громова составляла - 242,1 тыс. руб., Кушнарева - 50,8 тыс. руб., Санникова - 86 тыс. руб. ${ }^{2}$ Следует отметить, что в 1898 г. предприятие Громовых лидировало в скупке лисицы сиводушки, доля которой в общем объеме скупки составляла $15 \%{ }^{3}$. Северные промысловые районы кроме ценной пушнины были богаты мамонтовой костью, оптовая торговля которой давала северному купечеству высокие нормы прибыли. В 1900 г. Громовы скупили в северных промысловых районах 1000 пудов мамонтовой кости на сумму 25 тыс. руб., Кушнаревы - 800 пудов на сумму 20 тыс.

${ }^{1}$ НАРС (Я). Ф. 343. Оп. 1. Д. 585. Л. 67-69 об.

2 Там же.

3 Там же. Л. 56-78 об. 
руб., Санниковы $-1,5$ тыс. пудов общей стоимостью 34 тыс. руб. ${ }^{4}$ Средняя прибыль от торговли мамонтовой костью на ярмарках и с зарубежными покупателями в конце XIX - начале XX вв. составляла 38 \%.

Северо-восточные промысловые районы Якутской области были охвачены торговыми операциями Г. В. Никифорова и его компаньонов - И. П. Антипина, М. Г. Васильева. Особенностью северо-восточных промысловых районов было то, что здесь добывались особо ценные сорта белого и голубого песца, черно-бурая лисица, темные сорта белки, горностая и красной лисицы.

В 1899 г. предприятие Г. В. Никифорова скупило в северо-восточных промысловых районах 12 тыс. шкурок темной белки, 35 тыс. шкурок светлой белки, 14 тыс. шкурок белого песца, 1,5 шкурок голубого песца 5 . При этом, Г. В. Никифоров и его компаньоны являлись лидерами отрасли в скупке песца, доля которого в общем объеме скупки пушнины на территории Северо-Восточной Сибири составляла $82 \%{ }^{6}$. Общая стоимость пушнины, скупленной предприятием Г. В. Никифорова в северо-восточных промысловых районах в 1899 г. составляла 83 тыс. руб.7 Кроме пушнины, Г. В. Никифоров поставлял на общероссийский и зарубежный рынок мамонтовую кость, объемы ежегодной скупки которой, достигали размера более 80 тыс. руб. ${ }^{8}$ Средняя норма прибыли от оптовой торговли мамонтовой костью фирмы Г. В. Никифорова составляла $29 \%$.

Восточные промысловые районы занимали обширные пространства и выходили к побережью Охотского моря. Здесь наибольшее влияние имели предста-

${ }^{4}$ НАРС (Я). Ф. 1412. Оп. 2. Д. 173. Л. 12-13.

${ }^{5}$ Там же. Ф. 415. Оп. 1. Д. 1. Л. 4.

6 Там же. Ф. 343. Оп. 1. Д. 585. Л. 56-78 об.

7 Там же. Ф. 415. Оп. 1. Д. 1. Л. 4.

8 Там же. Л. 5-78. 
вители купцов М. А. Коковина и И. А. Басова. В 1898 г. ими было скуплено 52 тыс. шкурок темной белки, 10 тыс. шкурок светлой белки, 6 тыс. шкурок горностая, 685 шкурок красной лисицы. Общая стоимость пушнины предприятия М. А. Коковина и И. А. Басова в 1898 г. составляла 431 тыс. руб. ${ }^{9}$ Следует отметить, что фирма Коковина и Басова вела равномерную закупку всех видов пушнины. Доля темной белки в совокупном объеме закупок составляла 30 \%, светлой белки - $13 \%$, горностая - 14 , красной лисицы - 17 , лисицы сиводушки $-16 \%{ }^{10}$.

Высокие темпы роста капитала в оптовой пушной торговле в восточных промысловых районах Северо-Восточной Сибири имели А. В. Суворов и М. В. Калинкин, которые ежегодно поставляли на Якутскую ярмарку пушнину на 95 тыс. руб. ${ }^{11}$

Западные промысловые районы Якутской области, расположенные в долине р. Вилюй, были охвачены коммерческой деятельностью М. М. Бережнова. Якутский купец специализировался на операциях со светлой белкой, которую закупал у промыслового населения ежегодно на сумму 75 тыс. руб. ${ }^{12}$

Юго-восточные промысловые районы Северо-Восточной Сибири являлись привлекательными местами для расселения соболя. Промысловые районы Алдана были охвачены торговой деятельность Н. Д. Эверстова и его сыновей. Их главной задачей в ходе разъездной пушной торговли была скупка и концентрация в своих руках крупных партий соболей ${ }^{13}$. В период 18601878 гг. организация пушной торговли Н. Д. Эверстовым в юго-восточных промысловых районах характеризовалась высокой активностью.

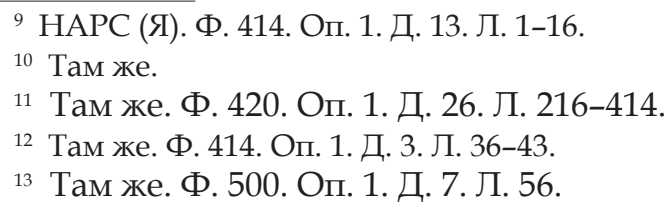


Так, в 1860 г. Н. Д. Эверстовым было скуплено соболей на сумму 15 тыс. руб., в 1861 г. - 11 тыс. руб., 1862 г. - 31 тыс. руб., в 1863 г. - 59,5 тыс. руб., 1864 г. - 183 тыс. руб., 1865 г. - 191 тыс. руб., 1866 г. 217 тыс. руб., 1867 - 800 тыс. руб., 1870 г. - более 1 млн руб. Прибыль от пушной торговли с Китаем в 1865-1878 гг. составляла около 700 тыс. руб. [3, с. 34]. В период 1871 - 1878 гг. объемы скупки одного только соболя Н. Д. Эверстовым составляли более 1 млн руб. ежегодно ${ }^{14}$. Организация пушной торговли Н. Д. Эверстовым в юго-восточном промысловом районе позволила ему сформировать достаточно высокий уровень концентрации капитала. Так, в 1867 г. годовой оборот предприятия Н. Д. Эверстова составлял более 800 тыс. руб., в 1871 г. - 1900 тыс. руб..

Благодаря наличию системы торгового районирования, северное купечество в короткие сроки сумело сформировать крупный капитал с высокими нормами прибыли. Динамика формирования прибыли в оптовой пушной торговле купеческих предприятий в Северо-Восточной Сибири в процентном соотношении выражалась следующим образом. Средний совокупный рост прибыли в 1867 г. составил $25 \%, 1868$ г. - $65 \%$, 1869 г. $-75 \%, 1872$ г. $-96 \%, 1876$ г. $-58 \%^{16}$.

Далее следует отметить, что наличие системы торгового районирования обусловило появление внутренней торговой специализации каждого купеческого предприятия.

Так, Н. Д. Эверстов специализировался на торговле соболем, Г. В. Никифоров - песцом, А. М. Кушнарев, И. Г. Громов - песцом, темной белкой, горностаем, лисицей, М. А. Коковин и И. А. Басов - концентрировали крупные партии светлой белки ${ }^{17}$.

14 НАРС (Я). Ф. 500. Оп. 1. Д. 1. Л. 1-45.

15 Там же.

16 Там же. Д. 12. Л. 1-18.

17 Там же. Ф. 511. Оп. 1. Д. 1. Л. 18; Ф. 414. Оп. 1. Д. 3. Л. 18. 
Кроме того, обширная территория, разделенная на сферы торговой деятельности, большие затраты времени в ходе разъездной торговли послужили основой формирования системы агентов, клиентов и доверенных лиц купцов. Клиенты или доверенные лица вели скупку пушнины в кредит в денежной или натуральной форме.

Так, в 1860-1879 гг. в юго-восточных промысловых районах Северо-Восточной Сибири Н. Д. Эверстов принял на баланс пушнину в счет уплаты денежного и натурального кредита от 23 доверенных лиц, каждый из которых кредитовался на сумму от 1,5 до 3 тыс. руб. под 12 \% годовых ${ }^{18}$. От имени А. М. Кушнарева в северных промысловых районах Северо-Восточной Сибири торговлю пушниной в 1896 г. вели 13 доверенных лиц $^{19}$. В числе клиентов Г. В. Никифорова числилось 25 скупщиков, которые кредитовались на сумму от 3 до 10 тыс. руб. ${ }^{20}$ М. А. Коковин кредитовал более 30 клиентов в восточном промысловом районе на сумму от 1 до 10 тыс. руб. ${ }^{21}$ Свой круг клиентов существовал у Я. Ф. Санникова, которые вели скупку песца на островах Северного Ледовитого Океана.

Система торгового районирования, исключавшая свободную конкуренцию, формировала у каждого купца определенный круг промысловиков-должников. Каждый купец был заинтересован в увеличении размера долгового капитала. Как правило, сделки с промысловиками заключались в меновой форме с произвольной оценкой товара и пушнины. Приведем некоторые примеры таких сделок. Так, в 1866 г. Н. Д. Эверстов принял пушнину от Слепцова Ю. А. на сумму 32018 руб. в обмен на товары потребления и продукты. Партия состояла из 21106 шт. горностая,

${ }^{18} \mathrm{HAРС} \mathrm{(Я).} \mathrm{Ф.} \mathrm{500.} \mathrm{Оп.} \mathrm{1.} \mathrm{Д.} \mathrm{5.} \mathrm{Л.} \mathrm{1-55.}$

19 Там же. Ф. 511. Оп. 1. Д. 1. Л. 21.

${ }^{20}$ Там же. Ф. 415. Оп. 1. Д. 6. Л. 1.

${ }^{21}$ Там же. Ф. 414. Оп. 1. Д. 3. Л. 3. 
3099 шт. колонка, 1641 шт. красной лисицы, 436 шт. лисицы сиводушки, 17570 шт. белки ${ }^{22}$. В обмен на пушнину Слепцов Ю. А. получил от Эверстова Н. Д. 1 пуд табака, 10 фунтов свечей, 10 пудов спичек, масло, сахар, сухари, хлеб, мануфактуру, чай, табак, крупчатку, муку и медную посуду. Общая стоимость товаров потребления составила 35890 руб. по оценке Н. Д. Эверстова. При этом сумма более 3 тыс. руб. перешла на следующий сезон в качестве долга.

Аналогичная форма сделки использовалась в пушной торговле в восточном промысловом районе. Так, в 1879 г. М. А. Коковин отпустил Дьячкову Ф. М. 125 кирпичей чая и 3 пуда табака на сумму 4,8 тыс. руб. Для приобретения пушнины в будущий промысловый сезон Дьячкову Ф. М. было выдано наличными 2039 руб. В счет уплаты долга за прошлый сезон от Дьячкова Ф. М. было принято 1156 шкурок белого песца, 5 тыс. шкурок красной лисицы, 20 шкурок черно-бурой лисицы, 183 шкурки лисицы сиводушки, 1351 шкурка горностая, 13 тыс. шкурок светлой белки, 1933 шкурки колонка. Всего пушнины было принято на сумму 17194 руб. ${ }^{23}$ В расчеты по приемке пушнины от Дьячкова Ф. М. была включена сумма нового долга в размере 9815 руб., которая реально не существовала. Если к ней добавить денежный кредит в размере 2039 руб., то общая сумма долга Дьячкова Ф. М. на 1880 г. составляла 11854 руб.

Подобного рода сделки были характерны для всех фирм в период концентрации капитала. Их сущность заключалась в том, что купеческая наценка на товары потребления промысловикам составляла в среднем 200-300 \%. В некоторых случаях купеческая наценка могла увеличиваться до 700 \%. Это вело к тому, что промысловики находились в состоянии постоянного долга с обязательством расчета в будущем промысловом сезоне.

${ }^{22}$ НАРС (Я). Ф. 500. Оп. 1. Д. 12. Л. 1-8.

${ }^{23}$ Там же. Ф. 414. Оп. 1. Д. 13. Л. 12-18. 
Кроме того, система торгового районирования влияла на формирование рыночной стоимости пушнины. Рост ярмарочной стоимости белки, добытой в северном промысловом районе в 1898 г. составлял $23 \%$, красной лисицы - 55 \%, лисицы сиводушки - $15 \%$, песца -87 \%. Рост ярмарочной стоимости песца, добытого в северо-восточных и восточных промысловых районах, составлял 70-75 \%, лисицы - 40-50\% ${ }^{24}$.

В начале $\mathrm{XX}$ в. на территории Северо-Восточной Сибири были официально зарегистрированы несколько фирм с крупным капиталом, основу экономической деятельности которых составляла оптовая пушная торговля с коренным населением. К ним относятся торговые дома «Н. Д. Эверстов», «А. И. Громова и сыновья», «Наследники А. М. Кушнарева», «Г. В. Никифоров», «М. А. Коковин и И. А. Басов». В среднем оборотный капитал каждой из вышеперечисленных фирм в оптовой пушной торговле в Северо-Восточной Сибири составлял от 150 до 600 тыс. руб. Высокие нормы прибыли в пушной торговле послужили стимулом для привлечения крупного капитала, сформированного в других отраслях торговли и промышленности, таких, как: чайная, мануфактурная и кожевенная. В тоже время, система торгового районирования длительное время сдерживала проникновение капитала представителей кяхтинского, иркутского, московского купечества, создавших свои предприятия с целью организации оптовой пушной торговли.

Конкурентная борьба между фирмами с крупным капиталом за право ведения торговых операций в северных и северо-восточных промысловых районах Северо-Восточной Сибири, наиболее богатых ценными пушными ресурсами, разгорелась с 1908 г. после открытия отделений торговых домов «А. В. Швецов и сыновья», «А. и М. Молчановы и Быков».

${ }^{24}$ РГИА. Ф. 23. Оп. 10. Д. 118. Л. 89-90 об. 


\section{Список использованной литературы}

1. Зензинов В. М. Очерки торговли на севере Якутской области / В. М. Зензинов. - М. : Наука, 1916. - 95 с.

2. Константинов М. М. Пушной промысел и пушная торговля в Якутском крае / М. Константинов. - Иркутск : Гос. изд-во. Иркутское отделение, 1920. - 91 с.

3. Кушнарева М. Д. Пушная торговля в Северо-Восточной Сибири в переписке представителей фирм с крупным капиталом во второй половине XIX - начале XX вв./ М. Д. Кушнарева. - Иркутск : Изд-во ИГУ, 2017. - 173 с.

4. Старцев А. В. Сибирь и сопредельные территории: история, историография, методология / А. В. Старцев. - Барнаул : Изд-во БЮИ МВД России, 2016. - 445 с.

5. Энциклопедический словарь по истории купечества и коммерции Сибири. В 2-х т. / отв. ред. Д. Я. Резун. - Новосибирск : Гео, 2012. - Т. 1. - 450 с.

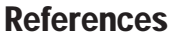

1. Zenzinov V. M. Ocherki torgovli na severe Yakutskoi oblasti [Essays about the trade in the North of the Yakutsk region]. Moscow, Nauka Publ., 1916. 95 p.

2. Konstantinov M. M. Pushnoi promysel i pushnaya torgovlya v Yakutskom krae [Fur trapping and fur trade in the Yakutsk region]. Irkutsk, State Publ., 1920. 91 p.

3. Kushnareva M. D. Pushnaya torgovlya v Severo-Vostochnoi Sibiri $v$ perepiske predstavitelei firm s krupnym kapitalom vo vtoroi polovine XIX - nachale XX vv. [Fur trade in Northeastern Siberia in correspondence of representatives of firms with a large capital in the second half of $19^{\text {th }}-$ the beginning of $20^{\text {th }}$ centuries.]. Irkutsk State University Publ., 2017. 173 p.

4. Startsev A. V. Sibir' $i$ sopredel'nye territorii: istoriya, istoriografiya, metodologiya [Siberia and adjacent territories: history, historiography, methodology]. Barnaul Law Institute of the Ministry of internal Affairs of the Russian Federation, 2016. 445 p.

5. Rezun D. Ya. (ed.) Entsiklopedicheskii slovar' po istorii kupechestva $i$ kommertsii Sibiri [Encyclopedic dictionary on the history of merchants and commerce in Siberia]. Novosibirsk, Geo, 2012, vol. $1.450 \mathrm{p}$.

\section{Информация об авторе}

Кушнарева Маргарита Дмитриевна - доктор исторических наук, доцент, доцент кафедры сервиса и сервисных 2018. T. 19, № 1. C. 79-90 
технологий Иркутского государственного университета. 664003, г. Иркутск, ул. К. Маркса, 1, e-mail: rita270880@mail.ru.

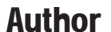

Margarita D. Kushnareva - D.Sc. in History, Associate Professor, Chair of Service and Service Technologies. Irkutsk State University, 1, Karl Marks st., Irkutsk, 664003, Russian Federation, e-mail: rita270880@mail.ru.

\section{Для цитирования}

Кушнарева М. Д. Роль системы торгового районирования в формировании фирм с крупным капиталом в Северо-Восточной Сибири во второй половине XIX - начале XX вв. / М. Д. Кушнарева // Историко-экономические исследования. - 2018. - Т. 19, № 1. - С. 79-90. DOI: 10.17150/2308-2588.2018.19(1).79-90.

\section{$47: 4 x^{3}$}

Kushnareva M. D. The Role of the Trade Regional System in the Formation of Firms with Large Capital in the North-Eastern Siberia in the Second Half of the $19^{\text {th }}$ - the Beginning of the $20^{\text {th }}$ Centuries. Istoriko-ekonomicheskie issledovaniya $=$ Journal of Economic History \& History of Economics, 2018, vol. 19, no. 1, pp. 79-90. DOI: 10.17150/2308-2588.2018.19(1).79-90. (In Russian). 